\title{
Assessment of Smoke Production from Building Products
}

\author{
ATLE WILLIAM HESKESTAD and PER JOSTEIN HOVDE \\ Department of Building and Construction Engineering \\ The Norwegian Institute of Technology, University of Trondheim \\ N-7034 Trondheim, Norway
}

\section{ABSTRACT}

By use of test data from the Cone Calorimeter bench scale test and two full scale fire tests (ISO Room Corner Test and CSTB Room Fire Test), relationships between smoke test data for the two scales were investigated. The study was based on test results for 38 products. Bench scale and full scale smoke production were normalized to either area burnt, mass loss or heat release and then compared. The most interesting parameter was smoke production per heat release, and for the products tested in the CSTB Room Fire Test there was found good correlation and a correlation coefficient of 0.99 . It was shown that smoke production in full scale was only about $45-60 \%$ of what was found in bench scale, and this is probably due to secondary combustion which occurs in the hot smoke layer. Before a secondary combustion occurs, the room fire is ventilation controlled and can produce more smoke than is found in bench scale. Thus the full scale fire influence smoke production in a way that may hinder relationship between bench scale and full scale smoke parameters. Full scale smoke test data from the ISO Room Corner Test were difficult to calculate, due to problems with finding the net heat release from the burnt products and the estimated burnt area. A one-to-one relationship between bench scale and full scale for the average effective heat of combustion $\left(\Delta \mathrm{h}_{c, \text { avg }}\right)$ was found and the plot obtained a correlation coefficient of 0.99 . Since direct mass loss measurements are not done in these full scale tests the smoke extinction area (SEA) is actually identical to smoke produced per heat release (TSP/THR).

KEYWORDS Building products, smoke assessment, bench scale tests, room fire scenario, correlations studies.

\section{INTRODUCTION}

The dominant hazard parameters in fires are the heat and smoke production. Smoke represents a hazard due to its toxic, irritating and optical obscuring effects [1], and it is the latter effect which is the main subject here. The obscuring effect itself is not considered as a danger, but by reducing the efficiency and speed of escape [1] the risk for the occupants to be exposed to lethal toxic gases (or heat) increases.

In different countries as well as international standardization organizations, smoke test methods have been developed in order to test combustible products for classification purposes. However, since it is shown that the methods give test results which rank combustible products differently and quite arbitrarily, their relationship to full fires has been questioned. 
If bench scale laboratory tests should be used to assess (and classify) combustible products, their relationship to real fire hazard should first be verified. In this paper such relationships are investigated for bench scale smoke test data produced by the Cone Calorimeter and full scale smoke test data produced either in the ISO Room Corner Test or the CSTB Room Fire Test.

Some progress has recently been done within this area [2] [3], but the physical understanding of the results is quite unknown [4].

The chosen method of investigation is to normalize the total smoke production on either area burnt, mass burnt or total heat release, and then compare the results from the different scales. The advantage of this method is that one-to-one comparison between similar smoke parameters from different scales can be done, and tendencies of eventual divergencies may be found.

\section{MATERIALS AND METHODS}

The paper is based on test data for 38 building products (cfr. table 1) tested in bench scale and full scale [5] [6] [7] [8] [9] [10]. All products are tested in bench scale by use of the Cone Calorimeter, in full scale 31 products are tested in the ISO Room Corner Test (product no. 1 - 32) and the other 7 products are tested in the CSTB Room Fire Test (product no. 60 - 71).

In the Cone Calorimeter [11] the specimen was mounted horizontally in a frame (exposed area $9,4 \mathrm{~cm} \times 9,4 \mathrm{~cm}$ ) and exposed to an electrically heated cone with an irradiance level of $50 \mathrm{~kW} / \mathrm{m}^{2}$ and an electric spark as pilot ignition. The smoke measurement system used was according to [12]. Both the total smoke production $\left(\mathrm{TSP}_{\mathrm{cc}}\right.$ ) and the total heat release (THR ${ }_{\mathrm{cc}}$ ) are measured from start of the test and until a mass loss criterium occurs $\left(2.5 \mathrm{~g} / \mathrm{m}^{2} \mathrm{~s}\right)$, and they are normalized to the exposed surface area (thus units $\mathrm{m}^{2} / \mathrm{m}^{2}$ and $\mathrm{MJ} / \mathrm{m}^{2}$ respectively).

In the ISO Room Corner Test [13], the specimens cover three walls and the ceiling. The room has a floor area of $7.2 \mathrm{~m}^{2}$, height $2.4 \mathrm{~m}$ and a (door-) opening of 0.8 $\mathrm{m} \times 2 \mathrm{~m}$. The burner is mounted in the rear corner and has an effect of $100 \mathrm{~kW}$ during the 10 first minutes, then it is raised to $300 \mathrm{~kW}$ for the next 10 minutes. However, the test is stopped if the heat release rate exceeds $1000 \mathrm{~kW}$ (which is definition of flashover). The fire parameters (heat release, smoke and gas production) are continuously measured in the exhaust duct (forced ventilation). Due to the comparison method, the tested products were divided into two groups; those which caused flashover before 10 minutes (14 products), and the others (17 products). These 17 products were further divided into two groups according to whether flashover occurred when the burner heat release was increased. For the 6 products which did not cause flashover the total smoke production and heat release were simply calculated for the whole test time, while for the other 11 products the total smoke production and heat release were calculated for only the first 10 minutes. For the 14 products which caused flashover before 10 minutes, the total smoke production and heat release were calculated from start of the test and until flashover. All values used in the comparisons are net values, ie. the contribution from the burner is subtracted. 
TABLE 1. Material data and full scale test data for the 38 building products studied.

(No) Building products $\begin{array}{ccc}\begin{array}{c}\text { Thickness } \\ (\mathrm{mm})\end{array} & \begin{array}{c}\text { Density } \\ \left(\mathrm{kg} / \mathrm{m}^{3}\right)\end{array} & \begin{array}{c}\mathbf{t}_{\text {Fo }} \\ (\mathrm{min}: \mathrm{s})\end{array}\end{array}$

1. Painted g.p.p.

2. Ordinary birch plywood

3. Textile wallcovering on g.p.p.

4. Melamine-faced high density non-comb. board

5. Plastic-faced steel sheet on mineral wool

6. FR particle board, type B1

7. Combustible faced mineral wool

8. FR Particle board

10. PVC-wallcarpet on g.p.p.

11. FR extruded polystyrene

12. Birch plywood

13. FR plywood

14. Melamine faced particle board

15. FR polystyrene

16. Particle board

17. Insulating wood fiber board

18. Medium density wood fiber board

19. Wood panel, spruce

20. Melamine faced particle board

21. PVC wallcovering on g.p.p.

22. Textile wallcovering on g-p.p.

23. Textile wallcovering on mineral wool

24. Paper wallcovering on g.p.p.

25. Rigid polyurethane foam

26. Expanded polystyrene

27. Paper wallcovering on g.p.p.

28. G.p.p.

29. PVC faced steel sheet on mineral wool

$30.0 .8 \mathrm{~mm}$ formaldehyde on noncomb. board

31. $1.4 \mathrm{~mm}$ formaldehyde on noncomb. board

32. Paint on steel plate

$60.10 \mathrm{~mm}$ plywood with surface coating

$61.8 \mathrm{~mm}$ particle board with surface coating

63. Polyisocyanurate with surface coating

67. Polyurethane with surface coating

69. Expanded polystyrene

70. Polymer wall-carpet on g.p.p.

71. PVC wall-carpet on g.p.p.

$\begin{array}{rrr}12 & 800 & \text { n.f. } \\ 12 & 600 & 2.30 \\ 12+1 & 800 & 11: 00 \\ 12+1.5 & 1055 & \text { n.f. } \\ 23+0.7+0.15 & 640 & \text { n.f. } \\ 16 & 630 & 10: 30 \\ 30+1 & 87 & 1: 20 \\ 12 & 750 & \text { n.f. } \\ 12+0.9 & 800 & 10: 55 \\ 25 & 37 & 1: 20 \\ 12 & 600 & 2: 17 \\ 9 & 620 & \text { n.f. } \\ 12+0.1 & 680 & 3: 02 \\ 25 & 30 & \text { n.f. } \\ 10 & 750 & 2: 30 \\ 13 & 250 & 0: 59 \\ 12 & 600 & 2: 11 \\ 11 & 530 & 2: 11 \\ 12+1 & 810 & 7: 45 \\ 13+0.7 & 700 & 10: 11 \\ 13+0.5 & 700 & 10: 29 \\ 50+0.7 & 150 & 0: 43 \\ 10+0.6 & 670 & 2: 23 \\ 30 & 30 & 0: 06 \\ 50 & 20 & 1: 55 \\ 13+0.6 & 700 & \text { n.f } \\ 13 & 700 & \text { n.f } \\ 13.15 & - & \text { n.f. } \\ 19+0.8 & - & \text { n.f. } \\ 19+1.4 & - & \text { n.f. } \\ 0.7+0.15 & - & 11: 50 \\ 10 & 470 & 6: 10 \\ 8 & 850 & 5: 40 \\ 30 & 47 & \text { n.f. } \\ 40 & 40 & 3: 50 \\ 79 & 14 & 6: 20 \\ 12+1.7 & - & 6: 20 \\ 12+1.1 & - & \text { n.f. } \\ 50+60 & & \end{array}$

$\mathrm{t}_{\mathrm{FO}}$ means time to flashover; g.p.p. means Gypsum paper plaster board; n.f. means no flashover (ie. RHR of $1000 \mathrm{~kW}$ was not reched within the test time)

The CSTB Room Fire Test [10] is developed by Centre Scientifique et Technique du Bâtiment (CSTB), France. The fire parameters are continuously measured during 25 minutes, regardless of the magnitude of the heat release rate. The room has a floor area of $10.4 \mathrm{~m}^{2}$, height $2.5 \mathrm{~m}$ and a (door-) opening of $0.9 \mathrm{~m} \mathrm{x} 2.0 \mathrm{~m}$. The fire source is a wood crib of weight $12-13 \mathrm{~kg}$ and with a maximum heat release rate of aproximately 380 $\mathrm{kW}$ after about 6 minutes. The exhaust system consists of a natural convection chimney, and for large heat release rates some overflow may occur. The specimens are mounted on the walls. In the tests described here the specimen area was varied for each product, thus each of the 7 products tested have full scale data averaged from 1 - 3 experiments. 
Both total smoke production and heat release are calculated from start of the test and until 25 minutes. All values are net values, ie. the effect of the wood crib is subtracted by use of separate test data from burning only the wood crib.

In all the test methods used the smoke measurements are done with an optical system either consisting of a white light or a laser (in [14] it is shown that optical smoke measurement done either with white light or a laser gives practically identical results). The smoke calculations are done according to Lambert-Beers law, thus the rate of smoke production (RSP $\left[\mathrm{m}^{2} / \mathrm{s}\right]$ ) and total smoke production (TSP $\left[\mathrm{m}^{2}\right]$ ) are defined as:

$T S P-\int_{0}^{t} R S P d t$ where $R S P=k \cdot V_{f}$ and $k=\frac{1}{L} \cdot \ln \left(\frac{I_{0}}{I}\right)$

where $V_{\mathrm{f}}$ is the volume duct flow $\left[\mathrm{m}^{3} / \mathrm{s}\right], \mathrm{k}$ is the light extinction coefficient $\left[\mathrm{m}^{-1}\right], \mathrm{L}$ path length and $I_{0}$ and $I$ incident and received light flux respectively.

\section{RESULTS}

\section{Introduction}

The smoke production normalized to the mass loss is defined as the smoke extinction area (SEA). The parameter varies during the test time, but here the averaged value is used:

$$
S E A_{\text {avg }}-\frac{R S P_{\text {avg }}}{R M L_{\text {avg }}}-\frac{T S P}{T M L} \quad\left[m^{2} / k g\right]
$$

where subscript avg denotes averaged values and RML and TML are rate of mass loss and total mass loss respectively.

The averaged heat of combustion ( $\Delta \mathrm{h}_{\mathrm{c}, \mathrm{avg}}$ ) is defined as:

$\Delta h_{c, a v g}=\frac{R H R_{\text {avg }}}{R M L_{\text {avg }}}-\frac{T H R}{T M L} \quad[M J / k g]$

where RHR and THR are rate of heat release and total heat release respectively.

$\mathrm{SEA}_{\mathrm{avg}}$ divided by $\triangle \mathrm{h}_{\mathrm{c}, \text { avg }}$ is the smoke production normalized to heat release:

$\frac{S E A_{\text {avg }}}{\Delta h_{c, a v g}}=\frac{R S P_{\text {avg }}}{R H R_{\text {avg }}}=\frac{T S P}{T H R} \quad\left[\mathrm{~m}^{2} / M J\right]$

\section{Comparison of Results from the Cone Calorimeter and the ISO Room Corner Test.}

Smoke production normalized to surface area. The burning area in the ISO Room Corner Test is unknown, but, according to Swedish studies [15], it can be assumed that the burning area $A_{b}$ behind the burner is about $2 \mathrm{~m}^{2}$ and $5 \mathrm{~m}^{2}$ for burner output of $100 \mathrm{~kW}$ and $300 \mathrm{~kW}$ respectively - if there is no progressive flame spread. 11 of the 17 products did not cause flashover at all, and for these it is assumed that the total smoke 
production originates from a $5 \mathrm{~m}^{2}$ burnt area. For the other 6 products which caused flashover some time after the burner output was increased to $300 \mathrm{~kW}$, the total smoke production is calculated only for the first 10 minutes, and then normalized to $A_{b}=2 \mathrm{~m}^{2}$.

The left part of figure 1 shows a correlation plot of equation (5):

$T S P_{c c} \propto \frac{T S P_{r s}}{A_{b}} \quad\left[\mathrm{~m}^{2} / \mathrm{m}^{2}\right]$

where subscript $\mathrm{cc}$ and rs relates to Cone Calorimeter and full scale (here the ISO Room Corner Test) respectively. In figure 1 (and the left part of figure 2) the 6 products which caused flashover before 10 minutes are marked with filled squares.

The 14 products which caused flashover within 10 minutes in full scale are only compared for smoke produced per heat release. Because they have had a progressive flame spread until flashover, their measured smoke production (until flashover) originates from an unknown area which may only be partly pyrolyzed, while the bench scale test data are based on total pyrolyzing of the specimen.
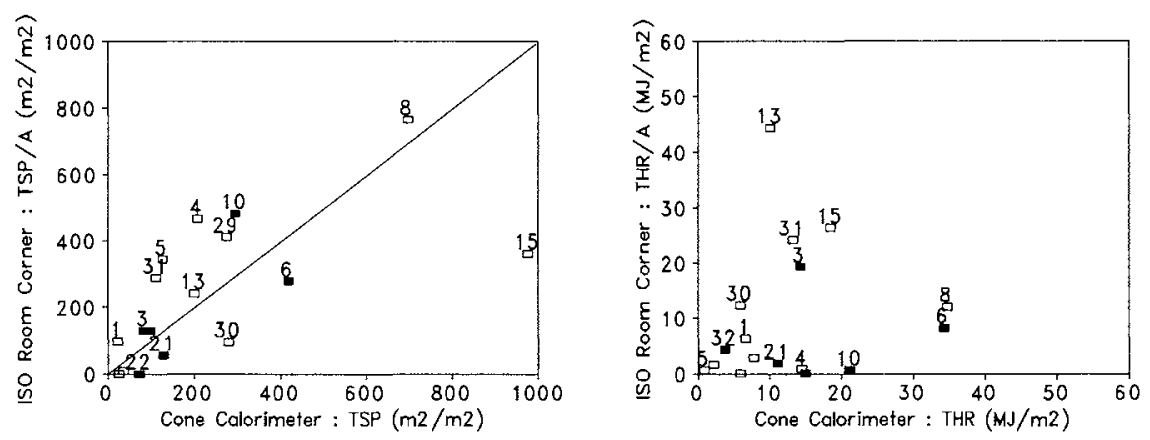

FIGURE 1. Comparison between the Cone Calorimeter and the ISO Room Corner Test. Left part: Comparison of smoke production per area burnt. Right part: Comparison of total heat release per area burnt.

The smoke extinction area (SEA). No direct mass loss measurements are done in the ISO Room Corner Test, thus the SEA must be found in another way than simply division by mass loss. This can be done by using the heat of combustion from the Cone Calorimeter (equation (3)) and a calculation according to equation (6):

$S E A_{a v g, r s}=\Delta h_{c, a v g, c c} \cdot \frac{T S P_{r s}}{T H R_{r s}} \quad\left[m^{2} / k g\right]$

Then a comparison between bench scale and full scale SEA could be done according to equation (7):

$S E A_{a v g, c c} \propto S E A_{a v g, r s} \quad\left[\mathrm{~m}^{2} / \mathrm{kg}\right]$

But if equation (3) is put into equation (7) it is found that equation (7) is identical to equation (8). 
Smoke production normalized to heat release. The left part of figure 2 shows the correlation plot of equation (8) for the 17 products which did not cause flashover before 10 minutes:

$$
\frac{T S P_{c c}}{T H R_{c c}} \propto \frac{T S P_{r s}}{T H R_{r s}} \quad\left[m^{2} / M J\right]
$$

Both products no. 5 and 29 should maybe be excluded from the plot because they have only a thin combustible surface layer on steel, and both the TSP and THR is small, thus inaccuracies could be critical. Thus no. 10 is not plotted as the full scale value exceeded the figure scale. Also this plot has a source of error, because it was hard to distinguish between the heat release of the burnt product and the burner, especially when the burnt product had a small heat release, and this often gave an underestimation of the net heat release. For this reason some of the products obtained negative heat release, and therefore these results are not plotted. This problem did not occur for the right part of figure 2, which is a plot of the 14 products which caused flashover before 10 minutes. Because these products have large heat release, the net THR is less sensitive for overestimation of the burner heat release.
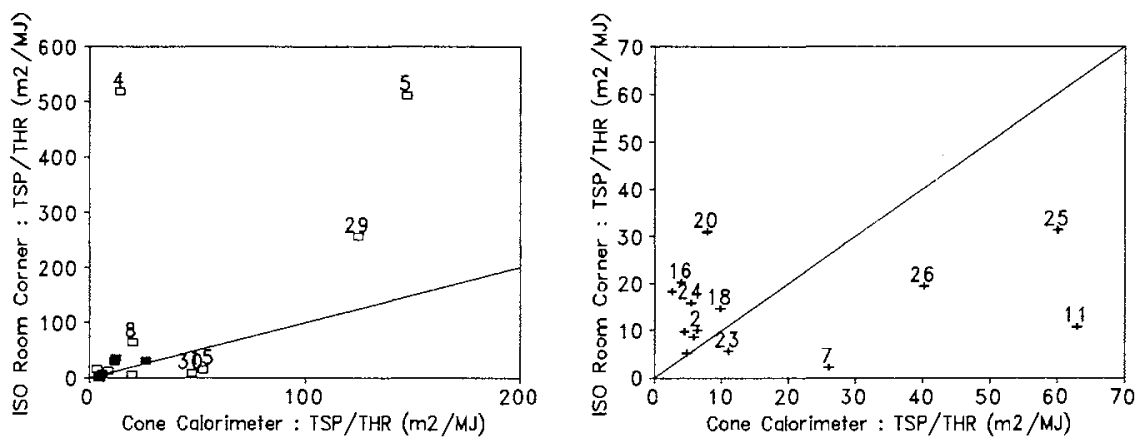

FIGURE 2. Comparison between the Cone Calorimeter and the ISO Room Corner Test. Left part: Comparison of smoke production per heat release for the 17 products which caused flashover eventually after 10 minutes. Right part: Comparison of smoke production per heat release for the 14 products which caused flashover before 10 minutes.

\section{Comparison of Results from the Cone Calorimeter and the CSTB Room Fire Test.}

In the CSTB Room Fire Test the actual mass of the specimen is found by weighing before mounting, and after the test the burnt area $\left(A_{b}\right)$ is measured. Thus more accurate comparisons can be made between the Cone Calorimeter and the CSTB Room Fire Test.

Smoke production normalized to surface area. The same comparison as given in equation (5) is done, but in addition corrections for the differences in density between the specimens in bench scale and full scale are made. The comparison is shown in the left part of figure 3. No. 63 is an outlier, and without this the drawn correlation line (with slope 0.46 ) obtains a correlation coefficient of 0.94 .

As the right part of figure 3 shows, there is nearly a one-to-one relationship between the total heat release from the two scales, and thus the estimation of $A_{b}$ is 
verified and it can also be assumed that the same degree of pyrolyzation has taken place. No. 71 is an outlier, probably because of not fully pyrolzed area. No. 63 is still an outler, and without this a drawn correlation line forced true 0 obtains a correlation coefficient of 0.99 (and a slope of 1.03).

Since no. 63 is an outlier in both plots of figure 3 and it appears on the upper side of the correlation lines, there may be an error in the calculations for this product.
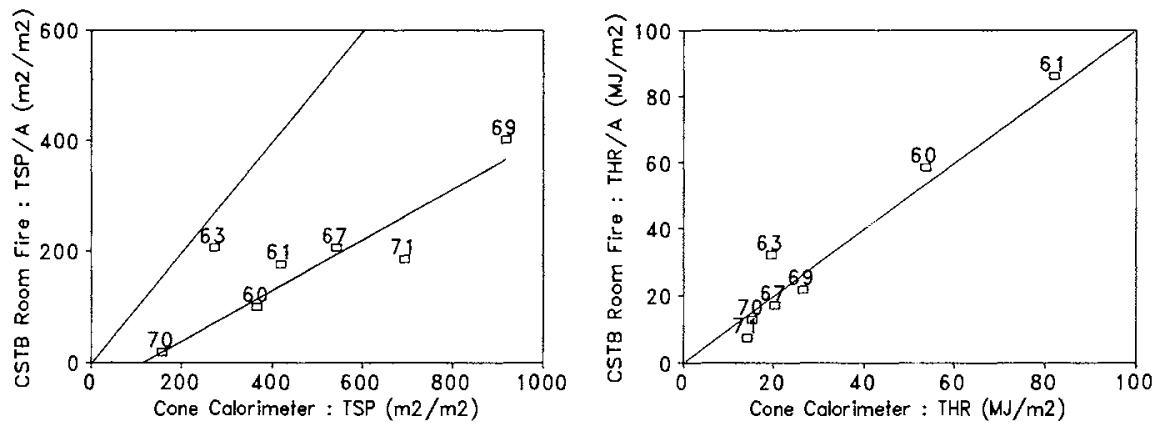

FIGURE 3. Comparison between the Cone Calorimeter and the CSTB Room Fire Test. Left part: Comparison of smoke production per area burnt. Right part: Comparison of the total heat release.

The smoke extinction area (SEA). Since the right part of figure 3 shows a one-toone relationship between THR from bench scale and full scale, it can be assumed that there is a similar degree of pyrolyzis in the two scales. Thus TML (and SEA) can be calculated based on the degree of pyrolyzis in bench scale and the burnt area in full scale, and then the comparison becomes identical to equation (5). Also equation (6) can be used to calculate $\mathrm{SEA}_{\mathrm{rs}}$, but then the comparison is identical to equation (8) except that the ranking changes.

Smoke production normalized to heat release: The plot is shown in the left part of figure 4 , and the correlation coefficient is 0.99 (all products included) for a correlation line with slope 0.59 .
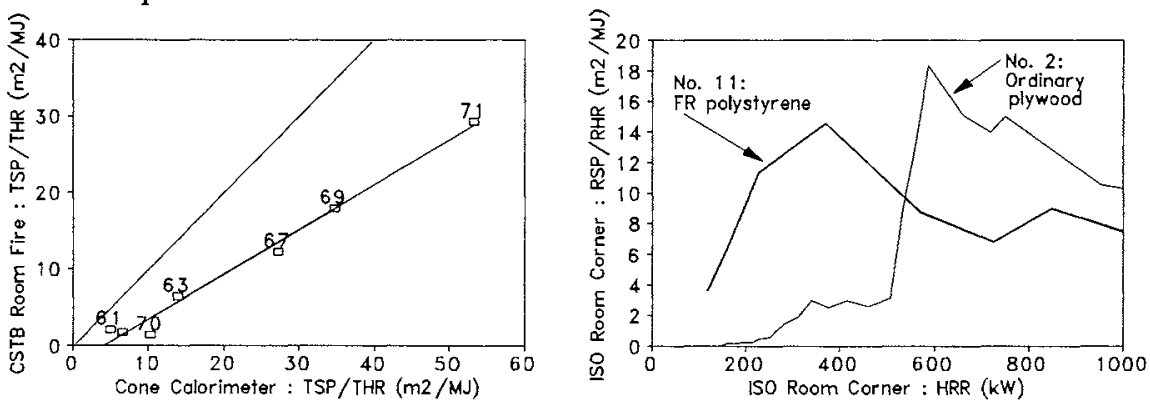

FIGURE 4. Left part: Comparison between the Cone Calorimeter and the CSTB Room Fire Test for smoke production per heat release. Right part: ISO Room Corner Test; RSP/RHR as a function of RHR. 


\section{DISCUSSION}

The main reason for this way of comparison is to relate the smoke production to another parameter which may have some proportionality with the smoke production. Thus the smoke production is normalized to either area burnt, mass burnt or heat release. And if smoke production parameters are roughly independent of scale or dependent in a general way, then correlations between bench scale and full scale exist.

Bench scale testing has shown that both $\mathrm{SEA}_{\mathrm{avg}}$ and $\Delta \mathrm{h}_{\mathrm{c}, \mathrm{avg}}$ are roughly independent of the irradiance level [14]. This means also that smoke production per area is independent of the irradiance level if the exposed area is fully pyrolyzed. Thus if these two parameters are used, the choice of the bench scale irradiance level should not affect the comparisons.

The right part of figure 1 shows that the assumption of a fully pyrolyzed area for 17 of the products tested in the ISO Room Corner Test was poor, and thus the smoke production per area burnt (ie. left part of figure 1) could hardly show any correlation.

This type of comparison was better for the 7 products tested in the CSTB Room Fire Test (cfr. left part of figure 3), because a better estimation of $A_{b}$ was done, and 6 of the 7 products were fully pyrolyzed in the full scale (shown by the right part of figure 3 ). The plot in the left part of figure 3 indicates that the full scale smoke production was significantly less and only about $45 \%$ of what was found in bench scale.

In the right part of figure 3 there is shown a one-to-one relationship between bench scale and full scale (CSTB Room Fire Test) total heat release per area burnt, and this means that $\Delta h_{c}$ is also independent of scale. Because this figure shows a one-to-one relationship, it can be concluded that the measurement of $A_{b}$ and the assumption of the same degree of pyrolyzis (ie. similar TML) are valid, and thus the same mass of material has been pyrolyzed in bench scale and full scale. And as the total heat release is material dependent and proportional to the mass loss, this means that the left part of figure 4 shows that smoke production and SEA are scale dependent. The figure indicates that full scale smoke production was less than the bench scale smoke production and only about $60 \%$ of what was found by bench scale testing.

In bench scale the specimen is tested under well ventilated conditions. The full scale fire in the room becomes ventilation controlled as the fire grows, and the degree of ventilation control is a function of the burning rate (ie. the heat release). For the ISO Room Corner Test the maximum heat release within the room has been estimated to around $600 \mathrm{~kW}$, due to the restricted ventilation [16]. Thus as the burning rate increases, the room fire becomes increasingly ventilation controlled, and the production of unburnt species as smoke and $\mathrm{CO}$ increases. But as the heat release increases, flames are observed in the upper layer inside the room and outside the opening (before the plume reaches the exhaust duct). This upper layer burning within and outside the room results in more complete combustion [17]. This is also in accordance with other experiments [18] where the tendency of external burning increased with plume equivalence ratio (ie. the degree of ventilation control), and where the secondary combustion in the upper layer resulted in a decreased equivalence ratio (ie. the fire became better ventilated) and significantly less production of smoke and $\mathrm{CO}$. And as the burning rate and the heat release increases until flashover while the ventilation decreases, it can be assumed that the occurrence of secondary combustion in the upper layer is a function of heat release. This indicate that the tendency to flames in the upper layer grows with increasing heat release. 
This upper layer burning can in some way be demonstrated by plotting the rate of smoke production normalized to the rate of heat release (ie. RSP/RHR) as a function of RHR. This is done for both product no. 2 ordinary plywood and no. $11 \mathrm{FR}$ polystyrene in the right part of figure 4 based on the test results from the ISO Room Corner Test. Due to the increasing ventilation control of the room fire, the production of unburnt species initially increases (ie. RSP/RHR inreases), but after some time RSP/RHR drops. The drop signifies that less smoke is produced (per heat released), and thus the combustion has become better. And this is probably due to a secondary combustion in the upper layer.

For the 17 products tested in the ISO Room Corner Test (cfr. left part of figure 2) hardly any general conclusion can be drawn, because the plot is not good. Neither any correlation is found for the 14 products which caused flashover before 10 minutes in the ISO Room Corner Test (ie. right part of figure 2). But the plot indicates that the synthetic polymer based products both had secondary combustion and that the ranking between bench scale and full scale seems to be preserved (cfr. no 7, 11,25 and 26 in the plot). This is not the case for the wood based products, but for these the full scale smoke production probably was increased due to ventilation control, and less secondary burning may have occured.

5 of 7 products tested in the CSTB Room fire Test caused flashover and generally had the main fraction of smoke produced under postflashover conditions. For these products the rankings were well preserved, indicating that there exists good relationship between bench scale and full scale.

Thus the secondary combustion in the upper layer is probably the reason for significantly less smoke production for the 7 products tested in the CSTB Room Fire Test. The main combustion in these tests occurs in the post-flashover situation, resulting in recombustion and significantly less produced smoke.

The results presented above show that there will be different modes of combustion between bench scale and full scale. Both bench scale and full scale have flaming combustion, but while the combustion in bench scale is well ventilated, the full scale combustion is initially ventilation controlled, but becomes better ventilated due to secondary combustion in the upper layer. Thus while full scale $\Delta \mathrm{h}_{\mathrm{c} \text {,avg }}$ is a parameter which is mainly a function of mass burnt, full scale SEA is not. And the success of correlating bench scale and full scale smoke parameters will depend on the full scale combustion conditions.

The results presented here should be born in mind if bench scale smoke parameters are used in computer based smoke prediction models.

When no direct mass loss measurements are done, SEA will be identical to the parameter smoke produced per heat release. However, since it is shown that $\Delta \mathrm{h}_{\mathrm{c}, \mathrm{avg}}$ is roughly scale independent, equation (6) can be used to find full scale $S E A_{\text {avg }}$. But the only difference between a plot for TSP/THR and SEA will then be the ranking of the products.

It should also be commented that the smoke from the wood crib in the CSTB Room Fire Test also burns in the upper layer. Thus the plotted correlation lines in the left part of figure 3 and 4 will cross the $Y$-axis below 0 , because a too large value of the smoke production from the crib is used to calculate the net smoke production from the tested products. 
Finaly it should be commented that the success of the correlation studies reported here is not fully understood, because if the secondary combustion burns smoke in the upper layer, this should also influence in some way on the ranking. Yet the left parts of figure 3 and 4 show that the ranking is preserved. The full scale smoke production is complex and yet not fully understood, and the investigations within this topic must continue.

\section{CONCLUSIONS}

By use of bench scale and full scale test data for 38 building products, relationships between smoke parameters were investigated. All products were tested in the Cone Calorimeter, whereas 31 were tested in the ISO Room Corner Test and the other 7 were tested in the CSTB Room Fire Test. The method of investigation was to normalize the measured total smoke production (TSP) to either area burnt, mass burnt or heat release and then compare between the two scales.

The 31 products which were tested in the ISO Room Corner Test were divided into two groups according to their time to flashover. For the 17 products which had an eventual flashover after 10 minutes, it was assumed that the smoke originated from a constant area which was fully pyrolyzed. For the other 14 products only TSP/THR until flashover were compared.

Smoke production per area burnt relies on the assumption that the exposed area is fully in depth pyrolyzed, but even if this is the case TSP/THR is a more interesting parameter. It was shown that the burnt areas for the 7 products tested in the CSTB Room Fire Test were fully pyrolyzed, whereas this was not the case for the 17 products in the ISO Room Corner Test.

If the room fire is allowed to burn out there seems to be good relationship between bench scale and full scale smoke parameters, and the product ranking was well preserved. For the 7 products tested in the CSTB Room Fire Test the smoke production in full scale was significantly less and only about $45-60 \%$ of what was found in bench scale. Probably this is a result of a secondary combustion in the upper layer. Still it is quite strange that totally this scenario burns the products more efficiently than in a wellventilated bench scale fire.

For the 17 products burnt in the ISO Room Corner Test where the data did not include any flashover conditions, any conclusions regarding smoke correlations can hardly be drawn because these products had little heat release, and it was difficult to distinct between the net heat release of the product and that of the burner. For the other 14 products tested in the ISO Room Corner Test there was a tendency to bigger smoke production in full scale for wood based products, while synthetic polymer based products tended to have significantly less smoke production in full scale. These results are probably a result of ventilation controlled full scale burning with and without a secondary combustion in the upper layer.

It was shown that the averaged smoke extinction area $\left(\mathrm{SEA}_{\mathrm{avg}}\right)$ is similar to smoke produced per heat release (ie. TSP/THR). However since the average effective heat of combustion $\left(\Delta \mathrm{h}_{\mathrm{c} \text {,avg }}\right)$ was shown to be roughly scale independent, bench scale $\Delta \mathrm{h}_{c, \text { avg }}$ can be used to estimate full scale $\mathrm{SEA}_{\mathrm{avg}}$. 
As a main conclusion the rate of smoke production in full scale can initially grow, but drops when a secondary combustion occurs in the upper layer.

The results indicate that bench scale smoke parameters only carefully should be used for full scale prediction, because the full scale combustion scenario both produces and destroys smoke in a way that makes the conversion of bench scale experimental results to full scale difficult and complex. Thus the bench scale ranking of the products, may become different in full scale.

\section{ACKNOWLEDGEMENTS}

The authors want to express sincere thanks to Birgit Östman and Lazaros Tsantaridis (Swedish Institute for Wood Technology Research, Sweden), Björn Sundström and Ulf Göranson (Swedish National Testing and Research Institute, Sweden) and Claude Moye and Bernard Hognon (Centre Scientifique et Technique du Bâtiment, France) for procuring essential experimental results. Thanks are also expressed to SINTEF NBL Norwegian Fire Research Laboratory for use of their Cone Calorimeter and their calculation programs.

The paper is partly based on results from a project funded by NORDTEST.

\section{REFERENCES}

1. Purser, D.A., Interactions between behaviour patterns and physiological impairment in escape from fire, Proceedings of Interflam '93, pp. 579-594, Interscience Communications, London, 1993.

2. Östman, B.A.-L. and Tsantaridis, L.C., "Smoke Data from the Cone Calorimeter for Comparison with the Room Fire Test", Fire and Materials, 17: 4, 191-200, 1993.

3. Heskestad, A.W. and Hovde, P.J., Smoke production from building products. Comparison of test methods and correlation of test results, Proceedings of Interflam '93, pp. 189-202, Interscience Communications, London, 1993.

4. Heskestad, A.W. and Hovde, P.J., Evaluation of Smoke Test Methods for Classification of Building Products. Nordtest Technical Report 220, Department of Building and Construction Engineering, Norwegian Institute of Technology, University of Trondheim, Norway, 1993.

5. Östman, B., Tsantaridis, L., Stensaas, J. and Hovde, P.J., Smoke Production in the Cone Calorimeter and the Room Fire Test for Surface Products Correlation Studies, The Swedish Institute for Wood Technology Research, Stockholm, Sweden, 1992.

6. Heskestad, A.W., "Smoke, Gas and Heat Release Test Data for French Building Products Tested in the Cone Calorimeter", Department of Building and Construction Engineering, Norwegian Institute of Technology, University of Trondheim, Norway, to be published. 
7. Lønvik, L.E. and Opstad, K., Software user's guide for DCS. A Data Converting System, SINTEF NBL Norwegian Fire Research Laboratory, Trondheim, Norway, 1991.

8. Mangs, J., Mikkola, E. and Kokkala, M, ISO Room/Corner test round robin report, ISO/TC92/SC1 Doc N 223, 1990.

9. Sundstöm, B., Full scale fire testing of surface materials, Swedish National Testing Institute, Borås, Sweden, 1986.

10. Hognon, B., Etude en vraie grandeur de la toxicité des effluents de combustion de produits de construction, Centre Scientifique et Technique du Bâtiment, Marne la Vallée, France, 1992.

11. ISO 5660 Fire tests - Reaction to fire - Rate of heat release from building products. International Organization for Standardization, Geneve, Switzerland, 1993.

12. ASTM E 1354 - 90. Standard Test Method for Heat and Visible Smoke Release Rates for Materials and Products Using an Oxygen Consumption Calorimeter. American Society for Testing and Materials, USA, 1990.

13. ISO 9705 Fire tests - Full scale room test for surface products. International Organization for Standardization, Geneve, Switzerland, 1993.

14. Tsantaridis, L. and Östman, B., Smoke, Gas and Heat Release Data for Building Products in the Cone Calorimeter, The Swedish Institute for Wood Technology Research, Stockholm, Sweden, 1989.

15. Wickström, U and Göransson, U., "Full-scale/Bench scale Correlations of Wall and Ceiling Linings", Heat Release in Fires, Elsevier Science Publishers Ltd.,Essex, England, 1992.

16. Karlsson, B., Modelling Fire Growth on Combustible Lining Materials in Enclosures, Lund University, Lund, Sweden, 1992.

17. Pitts, W.M., Executive Summary for the Workshop on Developing a Predictive Capability for CO Formation in Fires, pp. 15, 25, 33, National Institute of Standard and Technology, Gaithersburg, USA, 1989.

18. Gottuk, D.T., Roby, R.J. and Beyler, C.L., A study of carbon monoxide and smoke yields from compartment fires with external burning, Proceedings of the 24. Int. Symposium on Combustion, The Combustion Institute, Pennsylvania, USA, 1992. 